\title{
Amelioration of Cisplatin-Induced Nephrotoxicity in Rats by Curcumin and $\alpha$-Tocopherol
}

\author{
Sarawoot Palipoch ${ }^{1^{*}}$, Chuchard Punsawad ${ }^{1}$, Dutsadee Chinnapun ${ }^{1}$ and Prasit \\ Suwannalert ${ }^{2}$
}

${ }^{1}$ School of Medicine, Walailak University, Nakhon Si Thammarat, 80161, ${ }^{2}$ Department of Pathobiology, Faculty of Science, Mahidol University, Bangkok 10400, Thailand.

*For correspondence: Email: spalipoch@hotmail.com, sarawoot.pa@wu.ac.th; Tel: +66 75672873 Fax: +66 75672807

\begin{abstract}
Purpose: To investigate the possible protective role of curcumin and $\alpha$-tocopherol against cisplatininduced nephrotoxicity in rat.

Methods: Male Wistar rats were divided into five groups. Groups 1 and 2 were intraperitoneally (i.p.) injected with normal saline and cisplatin (20 mg/kg), respectively. Groups 3, 4 and 5 were pre-treated with a single doses of $\alpha$-tocopherol $(250 \mathrm{mg} / \mathrm{kg})$, curcumin $(200 \mathrm{mg} / \mathrm{kg})$ and $\alpha$-tocopherol with curcumin, respectively, for $24 h$ prior to the administration of cisplatin. After $72 h$ following injection, specimens were collected. Serum blood urea nitrogen (BUN), creatinine and malondialdehyde (MDA) levels, superoxide dismutase (SOD) and catalase activities, kidney histopathological study and gene expressions of nicotinamide adenine dinucleotide phosphate (NADPH) oxidase and p38 mitogenactivated protein kinase (p38-MAPK) were investigated.

Results: Pre-treatment with combined curcumin and $\alpha$-tocopherol exhibited significantly reduced MDA levels and enhanced activities of SOD and catalase compared with cisplatin-treated group $(p<0.05)$. It also improved BUN as well as creatinine levels and kidney histopathology. Moreover, gene expressions of NADPH oxidase were decreased, whereas p38-MAPK gene expressions were not significant compared with cisplatin-treated group.

Conclusion: Combined curcumin and a-tocopherol are able to reduce cisplatin-induced nephrotoxicity via possible inhibition of NADPH oxidase, resulting in improvement of kidney function and histology.
\end{abstract}

Keywords: Cisplatin, Oxidative stress, Curcumin, $\alpha$-Tocopherol, Nephrotoxicity.

Tropical Journal of Pharmaceutical Research is indexed by Science Citation Index (SciSearch), Scopus, International Pharmaceutical Abstract, Chemical Abstracts, Embase, Index Copernicus, EBSCO, African Index Medicus, JournalSeek, Journal Citation Reports/Science Edition, Directory of Open Access Journals (DOAJ), African Journal Online, Bioline International, Open-J-Gate and Pharmacy Abstracts

\section{INTRODUCTION}

Cisplatin or cis-diamminedichloroplatinum (II) is the chemotherapeutic agent useful in the treatment of various cancers such as ovarian cancer and testicular cancer [1]. Unfortunately, it exerts various side effects in several organs particularly in the kidney [2]. Only days after initiating treatment, approximately one-third of cisplatin-treated patients exhibit reduced glomerular filtration rate and increased blood urea nitrogen (BUN) and creatinine levels [3]. The underlying mechanism of nephrotoxicity remains incompletely understood. Oxidative stress has been implicated in the pathogenesis of kidney injury induced by cisplatin through increasing reactive oxygen species (ROS) resulting in augmented oxidation reaction of macromolecules especially lipid, protein and nucleic acid and reducing activity of enzymatic 
antioxidants such as SOD, glutathione peroxidase (GPX) and catalase [1,4]. ROS particularly superoxide radical $\left(\mathrm{O}_{2}{ }^{\circ-}\right)$ and hydroxyl radical $\left({ }^{\circ} \mathrm{OH}\right)$ play the important role in cisplatininduced acute renal failure by reducing renal blood flow and inducing tubular damage associated with increased renal contents of MDA, a biomarker of lipid peroxidation (LPO) [5]. NADPH oxidase is an enzyme which catalyzes the generation of $\mathrm{O}_{2}^{--}$in large amounts. $\mathrm{O}_{2}{ }^{--}$is able to rapidly change into other ROS such as hydrogen peroxide $\left(\mathrm{H}_{2} \mathrm{O}_{2}\right)$ and ${ }^{\circ} \mathrm{OH}$ [6]. Moreover, apoptosis also plays key role in cisplatin-induced renal cell injury [7]. Activated p38-MAPK has been implicated as a proapoptotic cellular signaling during oxidative stress [8].

Previous study provides evidence which supports that antioxidant supplementation is the important therapeutic strategy to abrogate kidney damage activated by cisplatin [9]. Curcumin, an active phenolic compound derived from the rhizomes of Curcuma longa used as a spice and food coloring shows various antioxidant abilities in vivo [10]. Treatment with curcumin has been reported to attenuate kidney dysfunction, histopathological alteration, oxidative stress and the reduced activities of enzymatic antioxidants induced by chemical agents [11]. The activity of curcumin alone is lower than that of the twocompound mixture [12].

Vitamin $E$ is a fat-soluble antioxidant and includes tocopherols and tocotrienols. Alphatocopherol is the most biologically active form of vitamin $E$. Curcumin and/or vitamin $E$ have been reported to exhibit effective antioxidant activity against L-thyroxine-induced rat testicular and hepatic oxidative stress [13]. The present study, therefore, aims to investigate the protective role of curcumin and $\alpha$-tocopherol against cisplatininduced oxidative stress in rat kidney.

\section{EXPERIMENTAL}

\section{Chemicals}

cis-Diamminedichloroplatinum (II), curcumin from Curcuma longa, a-tocopherol, Bradford assay kits and $10 \%$ neutral buffered formalin solution were purchased from Sigma-Aldrich Chemical Company (USA). Thiobarbituric acid reactive substances (TBARS), SOD and catalase assay kits were obtained from Cell Biolabs, Inc (USA). RNeasy mini kit, Omniscript RT kit and HotStar Taq DNA polymerase were purchased from Qiagen (Germany). All other chemicals were of analytical grade.

\section{Animals}

Twenty-five male Wistar rats (Rattus norvegicus), ranging from $180-200 \mathrm{~g}$ body weight (BW), were obtained from Division of Animal House, Faculty of Science, Prince of Songkla University, Thailand. All animal procedures were reviewed and approved by Animal Ethics Committee, Walailak University (Protocol no. 004/2012) and were conducted according to the Guide for the Care and Use of Laboratory Animals, National Research Council [14]. The rats were maintained in stainless-steel cages under constant conditions of temperature (23 \pm 2 $\left.{ }^{\circ} \mathrm{C}\right)$, relative humidity $(50-60 \%)$ and lighting (12 $\mathrm{h}$ light/dark cycles). They were provided with standard commercial rat feed (Division of Animal House, Faculty of Science, Prince of Songkla University, Thailand) and distilled water, and were acclimatized and closely monitored under laboratory conditions for 2 weeks prior to experimentation.

\section{Experimental design and specimen collection}

The rats were divided in five groups. Group 1 was treated with a single i.p. injection of normal saline. Group 2 was injected with a single dose of cisplatin (20 mg/kg, i.p.). Groups 3, 4 and 5 were treated with a single doses of a-tocopherol (250 mg/kg BW) alone, curcumin (200 mg/kg BW) alone and a-tocopherol (250 mg/kg BW) plus curcumin (200 mg/kg BW), respectively, via i.p. route, $24 \mathrm{~h}$ prior to a single-dose injection of cisplatin $(20 \mathrm{mg} / \mathrm{kg} \mathrm{BW})$. Seventy two hours (72 h) after the first injection, the rats were anesthetized with thiopental sodium intraperitoneally $(50 \mathrm{mg} / \mathrm{kg} \quad \mathrm{BW})$. Peripheral blood from heart was collected in clotted tubes and the rats euthanized by anesthetizing with an overdose of thiopental sodium (100 mg/kg BW). The abdominal cavity of rats was opened, the kidneys immediately collected and then washed in ice-cold isotonic saline.

\section{Determination of serum BUN and creatinine levels}

The peripheral heart blood samples were centrifuged at $3000 \mathrm{rpm}$ for $5 \mathrm{~min}$. Sera were collected and the levels of BUN and creatinine measured using a Cobas Mira Plus CC Chemistry Analyzer (Switzerland).

\section{Determination of MDA levels}

The kidney was re-suspended at $50 \mathrm{mg} / \mathrm{ml}$ in phosphate buffered saline (PBS) containing 1X butylated hydroxytoluene (BHT), homogenized on ice and centrifuged at $10000 \times \mathrm{g}$ for $5 \mathrm{~min}$ to 
collect supernatant. According to the protocol of OxiSelect ${ }^{\mathrm{TM}}$ TBARS Assay Kit (Cell Biolabs, Cat no: STA-330), $100 \mu$ l of sample or MDA standard was added to separate in microcentrifuge tubes; $100 \mu \mathrm{l}$ of the SDS lysis solution was added, mixed thoroughly, incubated for $5 \mathrm{~min}$ at room temperature, and $250 \mu \mathrm{l}$ of thiobarbituric acid (TBA) reagent added. Each tube was closed, incubated at $95^{\circ} \mathrm{C}$ for $60 \mathrm{~min}$, removed and then cooled to room temperature in an ice bath for 5 min. All the sample tubes were centrifuged at $3000 \mathrm{rpm}$ for $15 \mathrm{~min}$, the supernatant removed, and $200 \mu \mathrm{l}$ of which was transferred, along with $200 \mu \mathrm{l}$ of MDA standard, to a 96-well microplate compatible with a spectrophotometric plate reader (Syngene, USA) and the absorbance read at $532 \mathrm{~nm}$.

\section{Determination of SOD activity}

The kidney was homogenized to $50 \mathrm{mg} / \mathrm{ml}$ in cold 1X lysis buffer (10 mM Tris, $\mathrm{pH} 7.5,150 \mathrm{mM}$ $\mathrm{NaCl}, 0.1 \mathrm{mM}$ EDTA), centrifuged at $12000 \times \mathrm{g}$ for $10 \mathrm{~min}$ and the supernatant collected for analysis. According to protocol of OxiSelect ${ }^{\mathrm{TM}}$ SOD Activity Assay Kit (Cell Biolabs, Cat No: STA-340), $20 \mu$ l of the sample, $5 \mu$ l of xanthine solution, $5 \mu$ l of chromagen solution, $5 \mu$ l of $10 \mathrm{X}$ SOD assay buffer, $50 \mu$ of deionized water were mixed together to yield a total volume of $90 \mu \mathrm{l}$ in a 96 well microplate; $10 \mu$ of pre-diluted $1 \mathrm{X}$ xanthine oxidase solution was added to each well, mixed well, incubated for $1 \mathrm{~h}$ at $37^{\circ} \mathrm{C}$ and the absorbance read with a spectrophotometric plate reader at $490 \mathrm{~nm}$.

\section{Determination of catalase activity}

The kidney was homogenized to $50 \mathrm{mg} / \mathrm{ml}$ in cold PBS with $1 \mathrm{mM}$ EDTA, centrifuged at 10000 $\mathrm{x} g, 4{ }^{\circ} \mathrm{C}$ for $15 \mathrm{~min}$ and the supernatant collected. According to the protocol of OxiSelect $^{\mathrm{TM}}$ Catalase Activity Assay Kit (Cell Biolabs, Cat No: STA-341), $20 \mu$ of the diluted catalase standard or sample was added to a 96well microplate, $50 \mu \mathrm{l}$ of the $\mathrm{H}_{2} \mathrm{O}_{2}$ working solution (12 $\mathrm{mM}$ ) was added to each well, mixed thoroughly, incubated for $1 \mathrm{~min}$, and the reaction stopped by adding $50 \mu$ of catalase quencher into each well and mixed thoroughly; $5 \mu \mathrm{l}$ of each reaction well was transferred to a fresh well, 250 $\mu \mathrm{l}$ of the chromogenic working solution added to each well, incubated for $60 \mathrm{~min}$ with vigorous mixing and its absorbance read with a spectrophotometric plate reader at $520 \mathrm{~nm}$.

\section{Protein determination}

Protein content of kidney sample was determined in order to calculate MDA level as $\mathrm{nmol} / \mathrm{g}$ protein, SOD and catalase activities as U/mg protein by Bradford assay (Sigma, USA) using bovine serum albumin (BSA) as standard.

\section{Histopathological examination of kidney sample}

The kidney was preserved in $10 \%$ neutral buffered formalin solution for $24 \mathrm{~h}$ and washed with $70 \%$ ethanol. The tissue was then placed in small metal caskets, stirred by a magnetic stirrer, dehydrated using alcohol series from 70 to 100 $\%$ and embedded in paraffin using an embedding machine. Paraffin block was sectioned using a rotary ultra microtome, distributed onto glass slides and then dried overnight. The slide was observed under a light microscope after being stained with hematoxylin and eosin (H\&E) dyes and mounted. Two pathologists evaluated histopathological grading using a semi-quantitative scale: normal $=0$; mild $=<25 \%$; moderate $=25-50 \%$; severe $=>50$ $\%$ of affected area.

\section{Determination of NADPH oxidase and p38- MAPK gene expressions}

Total RNA was extracted from kidney tissue by RNeasy mini kit. RNA content and purity were measured by a UV spectrophotometer. RT-PCR was done using the extracted RNA for detection of NADPH oxidase and p38-MAPK genes. For amplification of the targets genes, reverse transcription and $\mathrm{PCR}$ were run in two separate steps. Briefly, Reaction mixture of RT reaction containing $1 \mu \mathrm{g}$ total RNA, $0.5 \mu \mathrm{g}$ random primer, $5 \times \mathrm{RT}$ buffer, $2.5 \mathrm{mmol} / \mathrm{l} \mathrm{dNTP}$, $20 \mathrm{U}$ RNase inhibitor and $200 \mathrm{U}$ MMLV reverse transcriptase in a total volume of $25 \mu \mathrm{l}$ was incubated at $37{ }^{\circ} \mathrm{C}$ for $60 \mathrm{~min}$, then heated to 95 ${ }^{\circ} \mathrm{C}$ for $5 \mathrm{~min}$ to inactivate MMLV. PCR was carried out with $1.5 \mu \mathrm{RT}$ products, $10 \times \mathrm{PCR}$ buffer (without $\mathrm{Mg}^{2+}$ ) $2.5 \mu \mathrm{l}, 2.0 \mu \mathrm{l}$ dNTP (2.5 $\mathrm{mmol} / \mathrm{l}), 2.0 \mu \mathrm{l} \mathrm{MgCl}_{2}(25 \mathrm{mmol} / \mathrm{l}), 0.5 \mu \mathrm{l}$ each primer $(20 \mu \mathrm{mol} / \mathrm{l})$ of $\beta$-actin, $0.5 \mu \mathrm{l}$ each primer of gene to be tested $(20 \mu \mathrm{mol} / \mathrm{l})$ and $1 \mathrm{U}$ of Taq DNA polymerase, in a final volume of $25 \mu \mathrm{l}$. Thermal cycler conditions were as follows: a first denaturing cycle at $97^{\circ} \mathrm{C}$ for $5 \mathrm{~min}$, followed by a variable number of cycles of amplification defined by denaturation at $96{ }^{\circ} \mathrm{C}$ for $1.5 \mathrm{~min}$, annealing for $1.5 \mathrm{~min}$ and extension at $72{ }^{\circ} \mathrm{C}$ for $3 \mathrm{~min}$. A final extension cycle of $72{ }^{\circ} \mathrm{C}$ for $15 \mathrm{~min}$ was included [15]. The primers, including NADPH oxidase, p38-MAPK and $\beta$-actin, are illustrated in Table 1.

All PCR products were electrophoresed on 2 $\%$ agarose stained with ethidium bromide and visualized by UV transilluminator. The amounts 
of PCR products were quantified using the gel and image analysis software (Syngene, USA).

Table 1: The primers of NADPH oxidase, p38-MAPK and $\beta$-actin

NADPH oxidase

Forward primer: 5'-GGAAATAGAAAGTTGACTGGCCC -3' Reverse primer: 5'-GTATGAGTGCCATCCAGAGCAG-3'

p38-MAPK

Forward primer: 5'TGACTTGCTTCCCTGTTCTTGA-3'

Reverse primer: 5'-TTTGGAAATGTGTCCACAGAGG-3'

$\beta$-actin

Forward primer: 5'TGTTGTCCCTGTATGCCTCT-3'

Reverse primer: 5'-TAATGTCACGCACGATTTCC-3'

\section{Statistical analysis}

The results were expressed as mean \pm standard deviation (SD). Differences between groups were determined by one-way analysis of variance (ANOVA). Post hoc test was performed for group comparisons using the least significant difference (LSD) test and $p<0.05$ was considered significant.

\section{RESULTS}

\section{Effect of treatments on kidney function biomarkers}

Cisplatin elicited a significantly increased serum $\mathrm{BUN}$ and creatinine levels compared with saline group $(p<0.05)$ (Fig 1). Although not significant, curcumin and/or $\alpha$-tocopherol were able to reduce BUN levels compared with cisplatintreated group (Fig 1A). Surprisingly, coadministration of curcumin and a-tocopherol produced significant reduction of creatinine levels $(p<0.05)$ compared with cisplatin-treated group. Additionally, curcumin or a-tocopherol lowered creatinine levels but not significantly (Fig 1B).

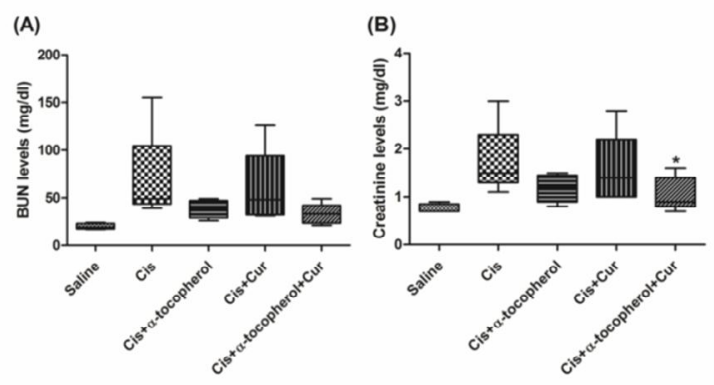

Fig 1: Kidney function test of rat study groups. (A) Serum BUN levels. (B) Serum creatinine levels. Values represent mean \pm SD $(\mathrm{n}=5) ;{ }^{*} p<0.05$ compared with cisplatin-treated group. Cis: cisplatin, Cur: curcumin

\section{Effect on lipid peroxidation and enzymatic antioxidant activities}

Cisplatin produced a markedly increased MDA levels compared with saline group $(p<0.05$, Fig $2 A)$ which indicate enhancement of lipid peroxidation. Cisplatin pre-treated with curcumin and/or a-tocopherol-treated groups showed a significant reduction in MDA levels compared with cisplatin-treated group $(p<0.05)$. Surprisingly, cisplatin pre-treated with combined curcumin and a-tocopherol treated group demonstrated significantly reduced MDA levels compared with cisplatin pre-treated with $\alpha$ tocopherol or curcumin $(p<0.05)$. As shown in Fig $2 \mathrm{~B}$ and $2 \mathrm{C}$, cisplatin demonstrated marked reduction in SOD and calalase activities compared with the saline control group $(p<$ $0.05)$. Cisplatin pre-treated with curcumin and/or a-tocopherol treated groups showed significantly increased SOD and calalase activities compared with cisplatin-treated group $(p<0.05)$.

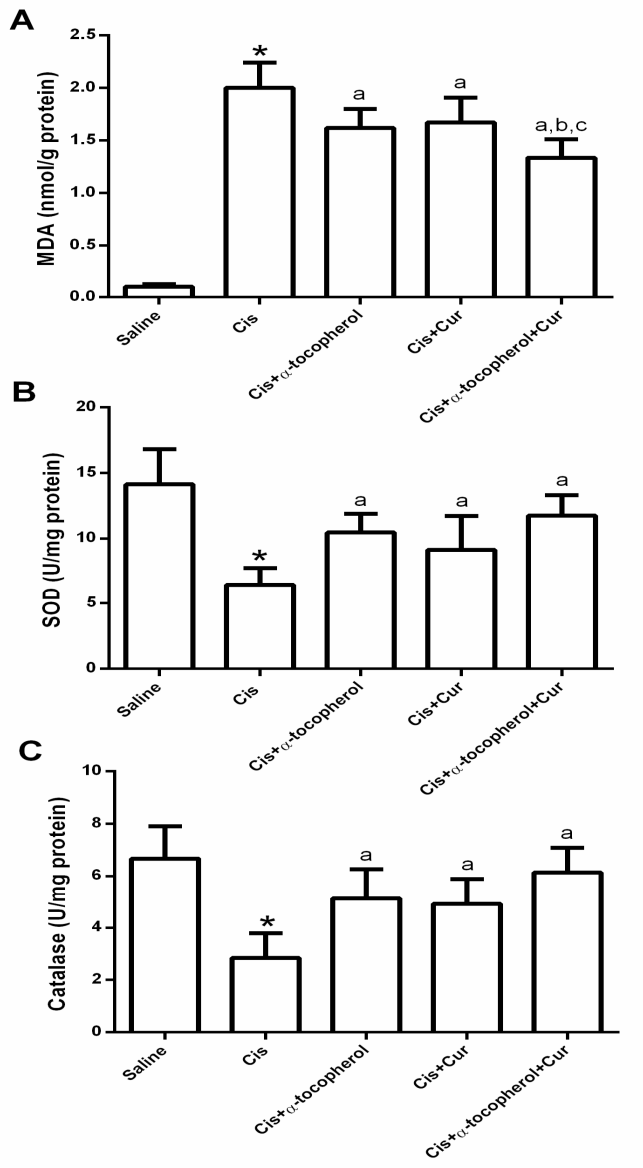

Fig 2: Lipid peroxidation and enzymatic antioxidant activities of the rats. (A) Renal MDA levels. (B) SOD activity. (C) Catalase activity. Values represent the mean \pm SD $(\mathrm{n}=5) ;{ }^{*} p<0.05$ compared with control group; ${ }^{a, b, c} p<0.05$ compared with cisplatin, cisplatin pre-treated with $\alpha$-tocopherol and cisplatin pre-treated with curcumin-treated groups, respectively. Cis: cisplatin, Cur: curcumin. 


\section{Effect of treatments on on kidney histopathology}

Cisplatin at $20 \mathrm{mg} / \mathrm{kg} \mathrm{BW}$ caused various pathologies of kidney especially in tubules including moderate accumulation of proteinaceous casts in tubular lumen, tubular necrosis and congestion (Fig 3C and 3D). Pretreatment with curcumin and/or a-tocopherol were able to improve kidney pathology induced by cisplatin (Fig 3E - J) (Table 2).

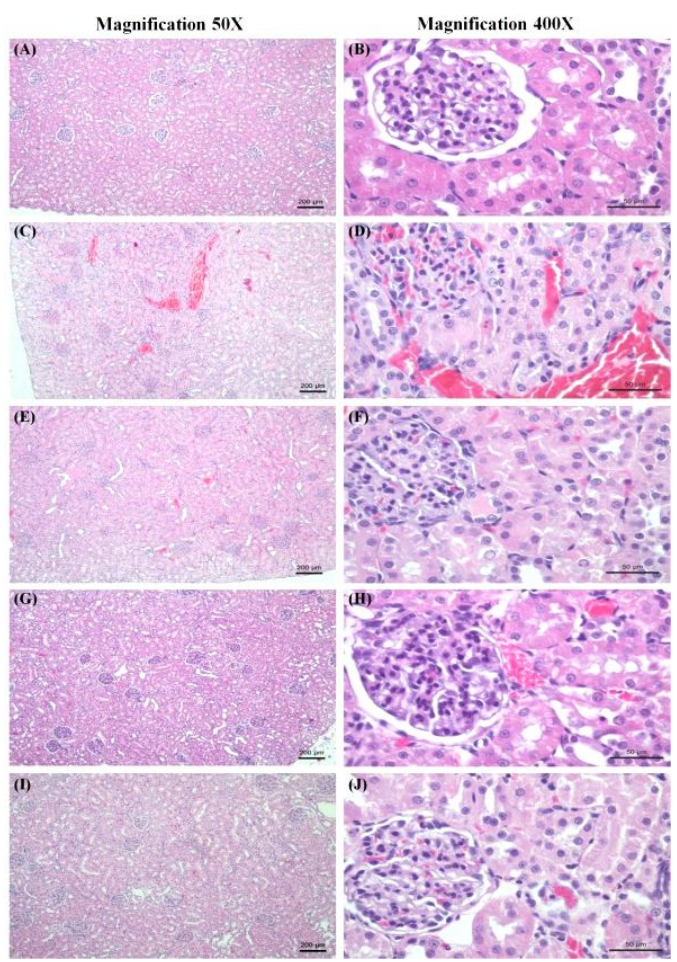

Fig 3: Effect of curcumin and/or a-tocopherol pretreatment on histopathological alterations upon cisplatin treatment in Wistar rats (H\&E staining): (A, B) Control group. (C, D) Cisplatin-treated group. (E, F) Cisplatin pre-treated with a-tocopherol-treated group. $(G, H)$ Cisplatin pre-treated with curcumin-treated group. (I, J) Cisplatin pre-treated with combined curcumin and $\alpha$-tocopherol-treated group. Scale: 200 and $50 \mu \mathrm{m}$ correspond to magnification at $50 \mathrm{x}$ and $400 \mathrm{x}$, respectively.

\section{Effect of treatment on NADPH oxidase and p38-MAPK gene expressions}

As shown in Fig 4A, treatment with cisplatin exhibited a significant enhancement of mRNA levels of NADPH oxidase compared with saline group $(p<0.05)$. Cisplatin pre-treated with combined curcumin and a-tocopherol-treated groups showed significantly reduction of mRNA levels of NADPH oxidase compared with cisplatin-treated group $(p<0.05)$. Although the effects were not significant, curcumin or $\alpha$ tocopherol reduced BUN levels compared with cisplatin-treated group. Cisplatin exhibited the increased mRNA levels of p38-MAPK but did not significant compared with saline group (Fig 4B). Additionally, cisplatin pre-treated with curcumin and/or a-tocopherol-treated groups did not reduce mRNA levels of p38-MAPK compared with cisplatin-treated group.

Table 2: Renal histological evaluation of the rats $(n=$ 5).

\begin{tabular}{lccccc}
\hline Histological & \multicolumn{5}{c}{ Group* $^{*}$} \\
\cline { 2 - 6 } alteration & $\mathbf{1}$ & $\mathbf{2}$ & $\mathbf{3}$ & $\mathbf{4}$ & $\mathbf{5}$ \\
\hline Accumulation of & 0 & $2+(4 / 5)$ & $0(2 / 5)$ & $0(3 / 5)$ & $0(4 / 5)$ \\
proteinaceous & & $3+(1 / 5)$ & $1+(2 / 5)$ & $1+(1 / 5)$ & $1+(1 / 5)$ \\
casts in tubular & & & $2+(1 / 5)$ & $2+(1 / 5)$ \\
lumen & & & & & \\
Tubular necrosis & 0 & $1+(1 / 5)$ & $0(3 / 5)$ & $0(3 / 5)$ & $0(3 / 5)$ \\
& & $2+(3 / 5)$ & $1+(1 / 5)$ & $1+(1 / 5)$ & $1+(1 / 5)$ \\
& & $3+(1 / 5)$ & $2+(1 / 5)$ & $2+(1 / 5)$ & $2+(1 / 5)$ \\
Congestion & 0 & $2+(5 / 5)$ & $0(3 / 5)$ & $0(3 / 5)$ & $0(4 / 5)$ \\
& & & $1+(2 / 5)$ & $1+(2 / 5)$ & $1+(1 / 5)$
\end{tabular}

Severity scores: 0 = Not found; 1+ = Mild; 2+ = Moderate; 3+ = Severe. ${ }^{*} 1$ = Control group; 2 = Cisplatin-treated group; 3 = Cisplatin pre-treated with a-tocopherol-treated group; $4=$ Cisplatin pre-treated with curcumin-treated group; $5=$ Cisplatin pre-treated with combined $\alpha$-tocopherol and curcumin-treated group.

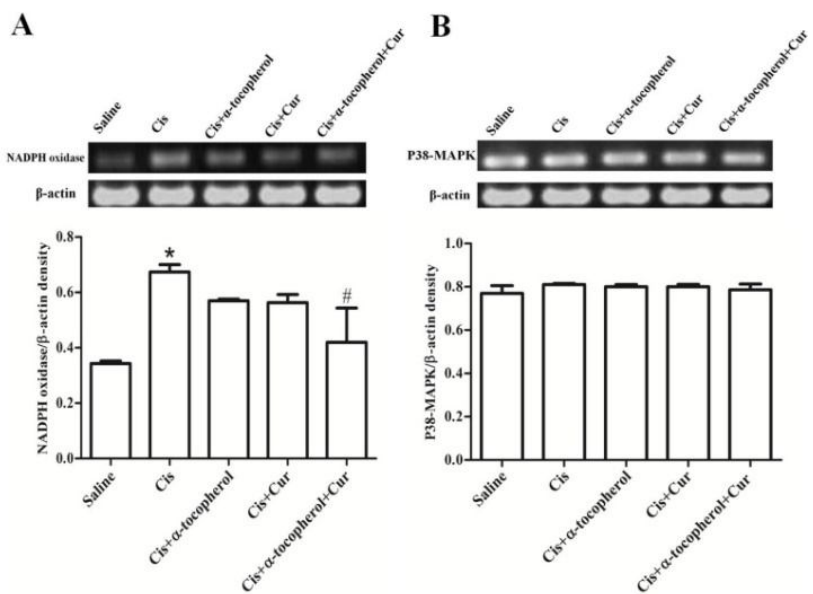

Fig 4: NADPH oxidase and p38-MAPK gene expressions in the rats. (A) Agarose gel electrophoresis showing gene expression of NADPH oxidase by RT-PCR with its density compared with $\beta$ actin. (B) Gene expressions of p38-MAPK with its density compared with $\beta$-actin. Values represent the mean $\pm \mathrm{SD}(\mathrm{n}=5) .{ }^{*} p<0.05$ compared with control group. ${ }^{\#} p<0.05$ compared with cisplatin. Cis: cisplatin, Cur: curcumin.

\section{DISCUSSION}

Normally, oxidative stress was caused by increasing oxidants and/or reducing antioxidants. Oxidants include ROS and reactive nitrogen species (RNS) which can be produced by both endogenous sources (inflammatory cells, fibroblast, epithelial cells, endothelial cells, respiratory chain, xanthine and NADPH oxidase) and exogenous sources (cigarette smoke, exogenous toxins, pollution, radiation, carcinogens and drugs) [16]. Under normal physiological conditions, oxidants are scavenged 
through antioxidant defense mechanism [17]. If incompletely clearance by antioxidants, oxidants will be caused oxidative stress. Inefficiency and insufficiency of antioxidant defense system are concerned in some pathological conditions induced by oxidative stress. Evidence of oxidative stress induced by cisplatin in kidney has been demonstrated in various studies $[1,4]$.

The present study demonstrated that oxidative stress contributes to cisplatin-induced nephrotoxicity by increasing MDA levels and reducing activities of enzymatic antioxidants including SOD and catalase, similarly to previous reports $[1,15]$. NADPH oxidase is a membranebound enzyme complex which donates an electron from NADPH to molecular oxygen $\left(\mathrm{O}_{2}\right)$ to produce $\mathrm{O}_{2}{ }^{\circ-}$. Thereafter, $\mathrm{O}_{2}{ }^{--}$is converted into $\mathrm{H}_{2} \mathrm{O}_{2}$ by SOD. $\mathrm{H}_{2} \mathrm{O}_{2}$ is also converted to ${ }^{\circ} \mathrm{OH}$ by the Fenton reaction. We suggest that cisplatin play a key role in ROS production by enhancement of NADPH oxidase gene expression causing increased lipid peroxidation, ultimately may caused membrane damage and cell death. Moreover, the present study illustrated that oxidative stress induced by cisplatin caused various kidney pathologies and increased serum BUN and creatinine levels, indicating kidney dysfunction.

The present study demonstrates that pretreatment with combined curcumin and $\alpha$ tocopherol could reduce gene expressions of NADPH oxidase, MDA levels, BUN and creatinine levels, and could increase activities of SOD and catalase. We suggest that curcumin and a-tocopherol acted as antioxidant to scavenge ROS, eventually abrogating oxidative stress and improve kidney pathology and function. Natural products-derived antioxidants are gradually high interest to investigate for reduce the side effects of cisplatin in various organs. Alpha lipoic acid plays a renoprotective role on cisplatin-induced nephrotoxicity through antioxidant and anti-apoptotic mechanisms in mice [1]. Chrysin or 5, 7-dihydroxyflavone which is present in honey and various plants revealed the protective effect against cisplatin-induced colon toxicity relating with attenuation of oxidative stress and apoptosis in male albino rats [18]. Caffeic acid phenethyl ester which is a flavonoid found in the honeybee propolis extract elicited partial protection against cisplatinassociated biochemical and histopathological alterations in the rabbit [19]. Powder of grain of Triticum sativum, Lisosan $\mathrm{G}$, also attenuated the oxidative stress and the preservation in antioxidant enzymes induced by cisplatin in renal and testicular tissues of male Wistar rats [20]. Additionally, cisplatin revealed not significantly increased p38-MAPK gene expression indicating that occurred cell death may not be associated apoptotic pathway. We suggested that necrotic pathway may be involved.

\section{CONCLUSION}

The present study has shown that oxidative stress plays an important role in nephrotoxicity induced by cisplatin. Pre-treatment with combined curcumin and a-tocopherol ameliorates cisplatin-induced nephrotoxicity via possible abrogation of oxidative stress. It also decreases gene expression of NADPH oxidase which is considered as one of the important endogenous sources of $\mathrm{O}_{2}{ }^{--}$. Moreover, the antioxidant effect is responsible for the reduction of lipid peroxidation and increased activities of SOD and catalase, resulting in improvement of kidney function and histopathology. Therefore, pre-treatment with combined curcumin and $\alpha$ tocopherol may be useful for patients undergoing chemotherapy by cisplatin but further in vivo studies and clinical trials are required to ascertain this.

\section{ACKNOWLEDGEMENT}

This research was supported by a grant from the Institute of Research and Development (under the contract WU 55307), Walailak University, Thailand. The authors are thankful to Dr. Phanit Koomhin for help with specimen collections, Miss Dararat Punwong, Medical Technologist from School of Allied Health Sciences and Public Health, Walailak University for laboratory assistance, and the Dean and staff of School of Medicine, Walailak University for their kind support.

\section{REFERENCES}

1. El-Beshbishy HA, Bahashwan SA, Aly HA, Fakher HA. Abrogation of cisplatin-induced nephrotoxicity in mice by alpha lipoic acid through ameliorating oxidative stress and enhancing gene expression of antioxidant enzymes. Eur J Pharmacol 2011; 668: 278284.

2. Palipoch S, Punsawad C. Biochemical and histological study of rat liver and kidney injury induced by cisplatin. J Toxicol Pathol 2013; 26: 293-299.

3. Pabla N, Dong Z. Cisplatin nephrotoxicity: mechanisms and renoprotective strategies. Kidney Int 2008; 73: 994-1007.

4. An $Y$, Xin $H$, Yan W, Zhou X. Amelioration of cisplatin-induced nephrotoxicity by pravastatin in mice. Exp Toxicol Pathol 2009; 63: 215219.

5. Matsushima H, Yonemura K, Ohishi K, Hishida A. The role of oxygen free radicals in cisplatin- 
induced acute renal failure in rats. $J$ Lab Clin Med 1998; 131: 518-526.

6. Babior BM. NADPH oxidase. Curr Opin Immunol 2004; 16: 42-47.

7. Jiang Z, Hu Z, Zeng L, Lu W, Zhang H, Li T, Xiao $H$. The role of the Golgi apparatus in oxidative stress: is this organelle less significant than mitochondria? Free Radic Biol Med 2011; 50: 907-917.

8. Zhou Y, Wang Q, Mark Evers B, Chung DH. Oxidative stress-induced intestinal epithelial cell apoptosis is mediated by p38 MAPK. Biochem Biophys Res Commun 2006; 350 : 860-865.

9. Yousef MI, Saad AA, El-Shennawy LK. Protective effect of grape seed proanthocyanidin extract against oxidative stress induced by cisplatin in rats. Food Chem Toxicol 2009; 47: 11761183.

10. M Khopde S, Priyadarsini KI, Venkatesan $P$, Rao $M N$. Free radical scavenging ability and antioxidant efficiency of curcumin and its substituted analogue. Biophys Chem 1999; 80: 85-91.

11. Ahmida MHS. Protective role of curcumin in nephrotoxic oxidative damage induced by vancomycin in rats. Exp Toxicol Pathol 2012; 64: 149-153.

12. Khalil OAK, de Faria Oliveira OMM, Vellosa JCR, de Quadros AU, Dalposso LM, Karam TK, Mainardes RM, Khalil NM. Curcumin antifungal and antioxidant activities are increased in the presence of ascorbic acid. Food Chem 2012; 133: 1001-1005.

13. Sahoo DK, Roy A, Chainy GBN. Protective effects of vitamin $E$ and curcumin on $1-$ thyroxine-induced rat testicular oxidative stress. Chem Biol Interact 2008; 176: 121128.

14. National Research Council. Guide for the care and use of laboratory animals. 8th ed. The National Academies Press, Washington DC, USA, 2011; pp 1-23.

15. Rashed LA, Hashem RM, Soliman HM. Oxytocin inhibits NADPH oxidase and P38 MAPK in cisplatin-induced nephrotoxicity. Biomed Pharmacother 2011; 65: 474-480.

16. Bargagli $E$, Olivieri $C$, Bennett $D$, Prasse $A$, Muller-Quernheim J, Rottoli $P$. Oxidative stress in the pathogenesis of diffuse lung diseases: a review. Respir Med 2009; 103: 1245-1256.

17. Halliwell B. How to characterize an antioxidant: an update. Biochem Soc Symp 1995; 61: 73101.

18. Khan R, Khan AQ, Qamar W, Lateef A, Tahir M, Rehman MU, Ali F, Sultana S. Chrysin protects against cisplatin-induced colon. toxicity via amelioration of oxidative stress and apoptosis: probable role of p38MAPK and p53. Toxicol Appl Pharmacol 2012; 258: 315-329.

19. Kart A, Cigremis Y, Karaman M, Ozen H. Caffeic acid phenethyl ester (CAPE) ameliorates cisplatin-induced hepatotoxicity in rabbit. Exp Toxicol Pathol 2010; 62: 45-52.

20. Longo V, Gervasi PG, Lubrano V. Cisplatin induced toxicity in rat tissues: the protective effect of Lisosan G. Food Chem Toxicol 2011; 49: 233-237. 